\title{
Effects of Ductus Venosus Obstruction on Liver and Regional Blood Flows in the Fetal Lamb
}

\author{
COLIN D. RUDOLPH, REBECKA L. MEYERS, RENE P. PAULICK, AND \\ ABRAHAM M. RUDOLPH \\ Cardiovascular Research Institute and the Departments of Pediatrics, Surgery and Obstetrics, Gynecology, and \\ Reproductive Sciences, University of California, San Francisco, California 94143
}

\begin{abstract}
The ductus venosus allows highly oxygenated blood returning from the umbilical-placental circulation to bypass the liver, and is believed thereby to facilitate preferential distribution of this blood to the fetal brain and heart. To examine this hypothesis, we developed a model that allows acute obstruction of the ductus venosus in chronically catheterized fetal lambs. In seven fetal lambs, a Swann-Ganz catheter was inserted into the inferior vena cava and the balloon tip advanced into the ductus venosus. Control measurements were obtained 1-2 d after surgery, before and during inflation of the balloon in the ductus venosus. At each sample time, radioactive microspheres were injected to determine organ blood flow and the distribution of umbilical venous blood flow. During balloon inflation, the percentage of umbilical venous return passing through the ductus venosus was reduced from $38 \pm 15 \%$ to $1 \pm 0.5 \%$. Umbilical-placental blood flow was unchanged from control values of $181 \pm 33 \mathrm{~mL} / \mathrm{min} / \mathrm{kg}$. Total liver blood flow increased from $346 \pm 98$ to $553 \pm 105 \mathrm{~mL} / \mathrm{min} /$ $100 \mathrm{~g}$. Pressure in the inferior vena cava did not change, but umbilical venous pressure increased from $7.2 \pm 2.7$ to $8.7 \pm 3.5 \mathrm{~mm} \mathrm{Hg}$. Total vascular resistance across the liver and ductus venosus increased from $0.013 \pm 0.006$ to $0.020 \pm 0.011$ during ductus venosus obstruction. Fetal heart rate, arterial blood pressure, and descending aortic pH and blood gases were unchanged, as was oxygen content in the descending aorta and carotid artery. Organ blood flows, combined ventricular output, and oxygen delivery were also unchanged. In five animals, these studies were repeated during maternal hypoxemia. Similar changes in liver blood flow were observed. Organ blood flows and oxygen delivery were not altered by ductus venosus obstruction during hypoxemia. We conclude that obstruction of the ductus venosus has no effect on regional blood flow distribution or oxygen delivery in normoxemic or hypoxemic animals. Because the hepatic microcirculation has such a high compliance, the ductus venosus is not crucial in regulating umbilical venous return to the central fetal circulation. (Pediatr Res 29: 347-352, 1991)
\end{abstract}

Up to $50 \%$ of the blood returning from the umbilical-placental circulation passes through the ductus venosus in the fetal lamb. The rest of the blood passes through the hepatic sinusoids and

Received September 26, 1990; accepted December 5, 1990.

Correspondence: Colin D. Rudolph, M.D., Ph.D., Division of Gastroenterology, ASB-4, Children's Hospital Medical Center, Elland and Bethesda Aves., Cincinnati, Ohio 45229-2899.

Supported by National Heart, Lung and Blood Institute Program Project Grant HL-24056 and a Deutsche Forschungsgemeinschaft Research Fellowship (DFG Pa 342/1-1) awarded to R. P. and a National Research Service Award (Training Gran No. HL 07192-12) awarded to R. L. M. then drains into the inferior vena cava. Streaming patterns in the inferior vena cava and right atrium preferentially distribute the highly oxygenated blood that passes through the ductus venosus to the fetal brain and heart (1). During umbilical cord compression (2) and fetal hemorrhage (3), increasing proportions of the blood returning in the umbilical vein from the placenta pass through the ductus venosus. These observations have suggested that the ductus venosus facilitates the preferential distribution of highly oxygenated blood to the fetal brain and heart.

However, the role of the ductus venosus is uncertain. The fetal foal, swine, and guinea pig lack a ductus venosus at term $(4,5)$. Previous studies in three late gestation, acutely exteriorized fetal lambs have suggested that ductus venosus constriction has no effect on carotid arterial $\mathrm{O}_{2}$ saturation or systemic blood pressure (6).

To explore the role of the ductus venosus and to examine the hypothesis that the ductus venosus facilitates the preferential distribution of highly oxygenated blood to the fetal brain and heart, we developed a model that permits intermittent ductus venosus obstruction in chronically catheterized fetal lambs. Using this model, we examined the effect of acute ductus venosus obstruction on oxygen and blood flow distribution to fetal organs in normoxemic and hypoxemic fetal lambs. We also measured alterations in hepatic vascular resistance and blood flow during ductus venosus obstruction.

\section{MATERIALS AND METHODS}

Animal preparation. Studies were approved by the Committee on Animal Research at the University of California, San Francisco. Seven fetal lambs, $129 \pm 3$ d gestational age (term, $147 \mathrm{~d}$ ) were fasted for $24 \mathrm{~h}$ before surgery. Epidural anesthesia was achieved in the ewe with $2 \mathrm{~mL}$ of $1 \%$ tetracaine hydrochloride. Ketamine was administered i.v. to the ewe $(100 \mathrm{mg}$ bolus every $10-15 \mathrm{~min})$ and intramuscularly to the fetus $(5 \mathrm{mg} / \mathrm{kg}$ estimated fetal weight before thoracotomy) for sedation. Local anesthesia with $0.25 \%$ lidocaine hydrochloride was used for all fetal incisions. The ewe received a continuous infusion of $10 \%$ dextrose in $0.9 \% \mathrm{NaCl}$ throughout the surgical procedure.

Polyvinyl catheters were inserted into a maternal pedal artery and vein and advanced to the descending aorta and inferior vena cava, respectively. In the fetus, polyvinyl catheters were inserted into the descending aorta, inferior vena cava, and umbilical vein as described previously (7). Briefly, a 3- to $4-\mathrm{cm}$ incision was made in the uterine horn over a fetal hind limb, through which catheters were inserted into both fetal pedal arteries and veins and advanced to the descending aorta and inferior vena cava, respectively. One of the catheters inserted into the inferior vena cava was advanced so that the tip was at the level of the diaphragm. The amnion was then separated from the allantoic membrane to expose a large umbilical vein along the mesenteric border of the uterus. A $3.5 \mathrm{~F}$ multiple side hole catheter was introduced into a small tributary entering the vein and was 
advanced $12-15 \mathrm{~cm}$ into one of the main umbilical veins. A second catheter was introduced $5-7 \mathrm{~cm}$ into the same vein for the injection of microspheres. An amniotic catheter was inserted, and the uterine incision was sutured.

The uterus was extracted further, and a second uterine incision was made over the right chest of the fetus and the right front leg was gently delivered through the incision. A catheter was inserted into the brachial artery and advanced into the brachiocephalic artery. The leg was returned into the uterus and the right chest of the fetus was exposed. The fetal lung was retracted through a right thoracotomy in the 8th intercostal space, exposing the inferior vena cava and diaphragm as described previously (8). A purse-string suture was placed in the inferior vena cava $0.5 \mathrm{~cm}$ cephalad to the entry of the diaphragmatic vein. The vessel wall was punctured in the center of the purse-string and a $4 \mathrm{~F} \mathrm{Swann-}$ Ganz catheter (American Edwards, Irvine, CA) was advanced $3.5 \mathrm{~cm}$ from the vessel wall into the ductus venosus. The catheter position was verified by comparing the oxygen saturation in the ductus venosus catheter with that in the umbilical vein. The fetal incision was sutured. Before closure of the uterine incision, lost amniotic fluid was replaced with warm $0.9 \% \mathrm{NaCl}$ solution. All catheters were tunneled through the skin to the ewe's flank. Catheter positions were ultimately verified by postmortem examination.

After surgery, the ewes recovered for at least $24 \mathrm{~h}$ before studies were performed; they received a standard diet of alfalfa pellets. All vascular catheters were flushed daily with heparin solution $(1 \mathrm{mg} / \mathrm{mL}$ ). Antibiotics (penicillin, $1000000 \mathrm{U}$, and kanamycin, $400 \mathrm{mg}$ ) were administered i.v. and instilled into the amniotic cavity daily.

Experimental protocol and measurements. Experiments were performed in seven animals 1 or $2 \mathrm{~d}$ after surgical preparation. Further time for recovery from surgery increased the risk of the Swann-Ganz catheter being dislodged from its location in the ductus venosus. The ewes stood quietly in study cages during the experiment. Fetal descending aortic, amniotic, inferior vena cava, and umbilical venous pressures were measured with carefully calibrated Statham P23Db pressure transducers. Pressures were recorded on a Beckman R612 direct writing recorder.

Control blood samples were withdrawn from the carotid artery, descending aorta, and umbilical vein for measurement of blood gases, $\mathrm{pH}, \mathrm{Hb}$ concentration, and oxygen saturation. Blood gases and $\mathrm{pH}$ were measured using a Corning 175 Blood Gas Analyzer (Corning Glass Works Medfield, MA). Hb concentrations and oxygen saturation were measured photometrically in duplicate (Hemoximeter OSM 2, Radiometer, Copenhagen, Denmark).

Blood flow measurements were obtained using $15-\mu \mathrm{M}$ radionuclide-labeled microspheres (9). Approximately 2 million microspheres were injected into the peripheral umbilical vein and approximately 1 million into the inferior vena cava simultaneously. Different isotope labels were randomly selected from ${ }^{51} \mathrm{Cr}$, ${ }^{54} \mathrm{Mn},{ }^{57} \mathrm{Co},{ }^{65} \mathrm{Zn},{ }^{85} \mathrm{Sr},{ }^{95} \mathrm{Nb},{ }^{113} \mathrm{Sn},{ }^{114} \mathrm{In}$, and ${ }^{153} \mathrm{Gd}$. Reference arterial blood samples were withdrawn from the carotid artery and descending aorta. The volume of blood withdrawn was replaced with fetal donor blood or, if this was not available, maternal blood.

The balloon tip of the Swann-Ganz catheter located in the ductus venosus was inflated with $0.5 \mathrm{~mL}$ of air. Blood samples and microsphere injections were repeated $10 \mathrm{~min}$ after balloon inflation. The balloon was deflated and the animal was allowed to recover for at least $1 \mathrm{~h}$. Blood pressure, heart rate, $\mathrm{pH}$ and blood gases, and blood lactate all were unchanged from control values before continuing the study.

In five animals, fetal hypoxemia was then induced by administering a gas mixture containing $3.5-7 \% \mathrm{O}_{2}$ and $2 \% \mathrm{CO}_{2}$ in nitrogen to the ewe via a loosely fitting plastic bag placed over her head. Fetal descending aorta oxygen saturation was checked every 3-5 min and the gas mixture adjusted to achieve approximately a $50 \%$ reduction in percent $\mathrm{O}_{2}$ saturation. After a 15 -min period of hypoxemia, blood samples and microsphere injections were repeated. The ewe was returned to room air and the animal was again allowed to recover for at least $1 \mathrm{~h}$. As noted above, blood pressure, heart rate, $\mathrm{pH}$ and blood gases, and blood lactate all were unchanged from control values before continuing the study. Fetal hypoxemia was again induced and after $5 \mathrm{~min}$ the balloon tip of the Swann-Ganz catheter was inflated to obstruct the ductus venosus. Samples were obtained and microspheres injected $10 \mathrm{~min}$ after balloon inflation.

The ewes were killed with an overdose of sodium pentobarbital followed by an i.v. injection of $10 \mathrm{~mL}$ saturated $\mathrm{KCl}$ solution. The uterus and individual fetal organs were dissected and weighed. All organs were placed in formalin, incinerated, and ground into a coarse powder for counting in a gamma scintillation counter. Using a multichannel (1024) pulse height analyzer (Norland, Fort Atkinson, WI), the activity of each isotope in each organ was determined using a least-square analysis method (10).

Calculations. Upper and lower body organ blood flows were calculated from the inferior vena cava injection of microspheres and carotid artery or descending aorta reference samples, respectively, such that:

$$
\mathrm{Q}_{\text {organ }}=\left(\mathrm{cpm}_{\text {organ }} / \mathrm{cpm}_{\text {reference }}\right) \times \mathrm{Q}_{\text {reference }}
$$

where $Q=$ blood flow and $\mathrm{cpm}=$ counts per min of the injected isotope (9). Blood flows are expressed as $\mathrm{mL} / \mathrm{min} / 100 \mathrm{~g}$ or $\mathrm{mL} /$ $\mathrm{min} / \mathrm{kg}$ fetal weight. Combined ventricular output was calculated by summing all the organ flows obtained from the inferior vena cava injectate and withdrawal volumes. Lung flow and potential superior vena cava flow across the foramen ovale were not accounted for, introducing a small error.

Previous studies have demonstrated (11) that the right lobe of the liver receives almost all of the portal venous blood and a contribution from the umbilical vein. The left lobe of the liver receives primarily umbilical venous blood. In the current studies, the hepatic artery contributed less than $3 \pm 2 \%$ of the total blood supplied to the right or left lobe. Therefore, we calculated liver and ductus venosus flows such that:

$$
\begin{gathered}
Q_{\text {left lobe }}=\left(\mathrm{cpm}_{\text {left lobe }} / \mathrm{cpm}_{\text {total fetus }}\right) \times Q_{\text {placenta }} \\
Q_{\text {right lobe }}=\left[\left(\mathrm{cpm}_{\text {right lobe }} / \mathrm{cpm}_{\text {total fetus }}\right) \times Q_{\text {placenta }}\right]+Q_{\text {portal vein }} \\
Q_{\text {poral vein }}=Q_{\mathrm{Gl} \mathrm{tract}}+\mathrm{Q}_{\text {spleen }} \\
Q_{\text {ductus venosus }}=\left[1-\left(\mathrm{cpm}_{\text {liver }} / \mathrm{cpm}_{\text {total fetus }}\right)\right] \times Q_{\text {placenta }}
\end{gathered}
$$

where $Q_{\text {placenta }}$ is calculated from the inferior vena cava injection as described above for calculations of lower body flows. Blood flows are expressed as $\mathrm{mL} / \mathrm{min} / 100 \mathrm{~g}$ organ tissue or $\mathrm{mL} / \mathrm{min}$ / $\mathrm{kg}$ fetal weight.

The above calculations require that microspheres injected into a peripheral branch of the umbilical vein mix adequately with umbilical venous blood before reaching the liver or ductus venosus. This assumption has been validated by two previous studies $(11,12)$ and has recently been reassessed in our laboratory by simultaneously injecting microspheres into the two main umbilical veins, one originating from the pregnant and the other from the nonpregnant horn of the uterus. Because the two main umbilical vessels join just beyond the umbilical ring to form the common umbilical vein, microspheres injected into a peripheral umbilical vein do not pass through a mixing chamber. Microspheres distributed to all other fetal organs pass through the heart, which acts as a mixing chamber. If mixing of microspheres in umbilical venous blood is inadequate, the coefficient of variation for ductus venosus and liver blood flows would be substantially higher than that for other organ blood flows. In fact, the coefficients of variation were not different for liver blood flows, ductus venous blood flows, and organ blood flows, which confirms that the distribution of microspheres injected into one umbilical vein represents the pattern of distribution of all the umbilical venous return (unpublished observation).

The vascular resistance $(\mathrm{R})$ across the umbilicus-placenta was 
calculated from the mean pressure difference between the descending aorta and umbilical venous catheter divided by the blood flow to the umbilicus-placenta. Vascular resistance across the ductus venosus and liver was calculated from the mean pressure difference between the umbilical vein and inferior vena cava divided by the blood flow, requiring the assumption that the pressure measured in the umbilical vein reflects that at the hilum of the liver. Because all of blood returning from the umbilicus-placenta passes through the ductus venosus or passes through the hepatic sinusoids and then drains into the inferior vena cava, we calculated the combined vascular resistance of the liver and ductus venosus based on the assumption that these two resistance sites are in parallel such that:

$$
I / R_{\text {liver and ductus venosus }}=1 / R_{\text {liver }}+1 / R_{\text {ductus venosus }}
$$

Values for vascular resistance are expressed as $\mathrm{mm} \mathrm{Hg} \cdot \mathrm{mL}^{-1}$. $\mathrm{min}^{-1} \cdot 100 \mathrm{~g}^{-1}$ organ tissue or $\mathrm{mm} \mathrm{Hg} \cdot \mathrm{mL}^{-1} \cdot \mathrm{min}^{-1} \cdot \mathrm{kg}^{-1}$ fetal weight.

Statistical analysis. Data analysis was performed using a computerized statistical program (Statview II; Abacus Concepts, Berkeley, CA). Data are expressed as mean \pm SD. Comparisons between the first two groups $(n=7)$ were made using a paired $t$ test. Comparisons between the four experimental periods $(n=$ 5) were made by one-way analysis of variance for repeated measurements. Multiple comparison testing was performed only if the analysis of variance first rejected a multisample hypothesis

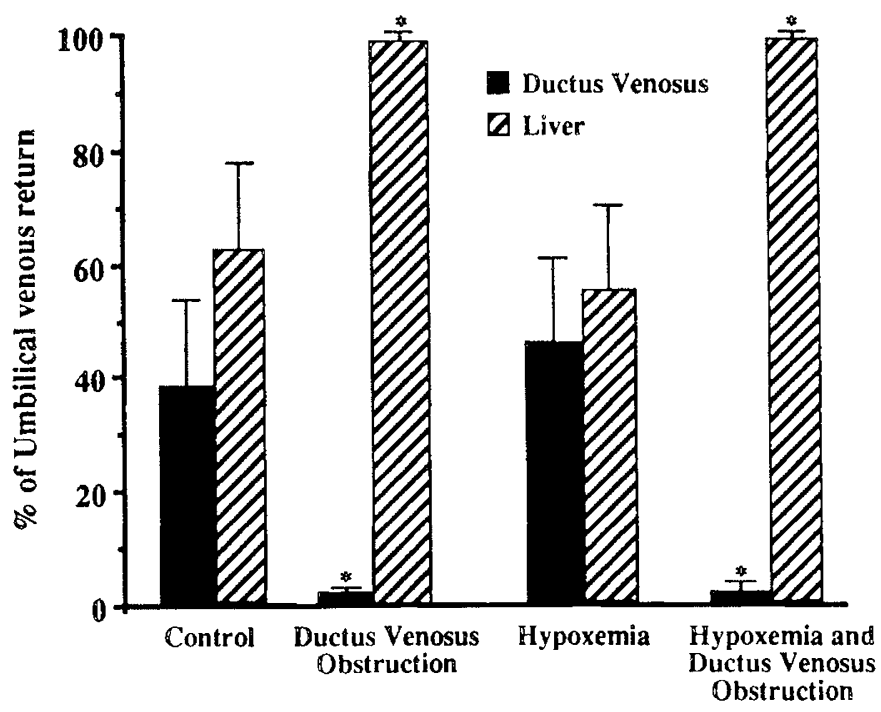

Fig. 1. Changes in the proportion of umbilical venous return passing through the liver and ductus venosus before and during ductus venosus obstruction in normoxemic $(n=7)$ and hypoxemic $(n=5)$ fetal lambs. ${ }^{*} p<0.001$ vs control and hypoxemia. of equal means with $p<0.05$. Differences between groups were then analyzed using the Scheffe multiple comparison $F$ test. For all tests, $p<0.05$ was considered statistically significant.

\section{RESULTS}

During the control period, $38 \pm 15 \%$ of the blood returning from the umbilical-placental circulation passed through the ductus venosus. After inflation of the balloon catheter, $1 \pm 0.5 \%$ of the umbilical venous return passed through the ductus venosus. Changes during hypoxemia and ductus venosus obstruction were similar to those observed in the nonhypoxemic animals (Fig. 1). This observation confirms our ability to obstruct the ductus venosus.

During obstruction of the ductus venosus there was no change in $\mathrm{pH}$, arterial blood gases, $\mathrm{Hb}$, and percent saturation of $\mathrm{Hb}$ (Table 1). Maternal hypoxemia caused reductions in $\mathrm{pH}$ and $\mathrm{Hb}$ saturation in the descending aorta and carotid artery as expected. The response to hypoxemia and ductus venosus obstruction was not different from hypoxemia alone. Before each intervention, blood $\mathrm{pH}$, arterial blood gases, $\mathrm{Hb}$, and percent saturation of $\mathrm{Hb}$ had returned to the initial control values.

Changes in heart rate and arterial and venous blood pressures are shown in Table 2. During ductus venosus obstruction, there were not even transient changes in arterial pressure, heart rate, or pressure in the inferior vena cava. There was a small increase in umbilical venous pressure in all seven animals from a mean value of $7.2 \pm 2.7$ to $8.7 \pm 3.5 \mathrm{~mm} \mathrm{Hg}(p<0.01)$. Hypoxemia increased umbilical venous pressure and decreased heart rate versus control values $(p<0.05)$. In four of five animals, there was a further increase in umbilical venous pressure during combined hypoxemia and ductus venosus obstruction, although these changes did not achieve statistical significance $(p=0.1)$. Heart rate, mean blood pressure, and pressures in the umbilical vein and inferior vena cava returned to the initial control values before each experimental intervention.

Changes in umbilical-placental and organ blood flows and combined ventricular output are shown in Table 3. Ductus venosus obstruction did not change umbilical-placental blood flow. Blood flow to the brain, heart, kidneys, gut, and spleen also did not change. There was no change in oxygen delivery to any organ during ductus venosus obstruction, inasmuch as blood flow and $\mathrm{O}_{2}$ content of blood did not change. During hypoxemia, adrenal, brain, and cardiac flow all tended to increase, whereas renal and carcass flows tended to decrease. Only the changes in adrenal flow achieved statistical significance $(p<0.001)$. Ductus venosus obstruction during hypoxemia did not alter organ flows.

Ductus venosus obstruction increased liver blood flow from $428 \pm 71$ to $627 \pm 119 \mathrm{~mL} / \mathrm{min} / 100 \mathrm{~g}(p<0.001)$. During ductus venosus obstruction, flow through the ductus venosus decreased from $70 \pm 26$ to $3 \pm 2 \mathrm{~mL} / \mathrm{min} / \mathrm{kg}$. Left liver flow increased from $57 \pm 27$ to $78 \pm 42 \mathrm{~mL} / \mathrm{min} / \mathrm{kg}$ and right liver

Table 1. Blood gases, Hb, and oxygen saturation in descending aorta and carotid artery before and during ductus venosus obstruction in normoxemic and hypoxemic fetal lambs*

\begin{tabular}{|c|c|c|c|c|}
\hline & $\begin{array}{l}\text { Control } \\
(n=7)\end{array}$ & $\begin{array}{c}\text { DV obstruction } \\
(n=7)\end{array}$ & $\begin{array}{c}\text { Hypoxemia } \\
(n=5)\end{array}$ & $\begin{array}{l}\text { DV obstruction } \\
\text { and hypoxemia } \\
\qquad(n=5)\end{array}$ \\
\hline \multicolumn{5}{|l|}{ Descending aorta } \\
\hline $\mathrm{pH}$ (units) & $7.37 \pm 0.03$ & $7.36 \pm 0.03$ & $7.30 \pm 0.07 \dagger$ & $7.30 \pm 0.08 \dagger$ \\
\hline $\mathrm{PCO}_{2}(\mathrm{kPa})$ & $6.88 \pm 0.82$ & $6.86 \pm 0.79$ & $7.80 \pm 1.16$ & $7.39 \pm 1.35$ \\
\hline $\mathrm{PO}_{2}(\mathrm{kPa})$ & $2.53 \pm 0.16$ & $2.76 \pm 0.40$ & $1.97 \pm 0.29 \dagger$ & $1.82 \pm 0.36 \dagger$ \\
\hline $\mathrm{Hb}(\mathrm{g} / \mathrm{L})$ & $109 \pm 28$ & $108 \pm 27$ & $107 \pm 10$ & $107 \pm 7$ \\
\hline Oxygen saturation (\%) & $46.6 \pm 8.0$ & $50.3 \pm 7.2$ & $24.5 \pm 6.5 \dagger$ & $20.3 \pm 4.6 \dagger$ \\
\hline \multicolumn{5}{|l|}{ Carotid artery } \\
\hline $\mathrm{Hb}(\mathrm{g} / \mathrm{dL})$ & $11.3 \pm 2.6$ & $10.9 \pm 2.5$ & $10.5 \pm 0.9$ & $10.8 \pm 0.6$ \\
\hline Oxygen saturation (\%) & $54.8 \pm 9.7$ & $57.0 \pm 7.8$ & $28.4 \pm 9.6 \dagger$ & $25.0 \pm 6.8 \dagger$ \\
\hline
\end{tabular}

* Values are given as mean $\pm \mathrm{SD}$. DV, ductus venosus.

$\dagger p<0.05$ vs control. 
Table 2. Heart rate and arterial and venous blood pressures before and during ductus venosus obstruction in normoxemic and hypoxemic fetal lambs*

\begin{tabular}{|c|c|c|c|c|}
\hline & $\begin{array}{l}\text { Control } \\
(n=7)\end{array}$ & $\begin{array}{l}\text { DV obstruction } \\
(n=7)\end{array}$ & $\begin{array}{c}\text { Hypoxemia } \\
(n=5)\end{array}$ & $\begin{array}{l}\text { DV obstruction } \\
\text { and hypoxemia } \\
\qquad(n=5)\end{array}$ \\
\hline Heart rate $(\mathrm{bpm})$ & $174 \pm 32$ & $169 \pm 21$ & $145 \pm 35 \dagger$ & $147 \pm 28 \dagger$ \\
\hline Descending aorta [mean pressure $(\mathrm{mm} \mathrm{Hg})$ ] & $48 \pm 4$ & $48 \pm 5$ & $52 \pm 4$ & $52 \pm 4$ \\
\hline Inferior vena cava $(\mathrm{mm} \mathrm{Hg})$ & $4.4 \pm 2.9$ & $4.5 \pm 3.6$ & $3.8 \pm 1.9$ & $4.1 \pm 2.1$ \\
\hline Umbilical vein $(\mathrm{mm} \mathrm{Hg}$ ) & $7.2 \pm 2.7$ & $8.7 \pm 3.5 \ddagger$ & $8.1 \pm 3.2 \ddagger$ & $8.6 \pm 3.4$ \\
\hline
\end{tabular}

* Values are given as mean $\pm \mathrm{SD}$. DV, ductus venosus.

$\dagger p<0.05$ vs control.

$\ddagger p<0.01$ vs control.

Table 3. Cardiac output and regional blood flows before and during ductus venosus obstruction in normoxemic and hypoxemic fetal lambs*

\begin{tabular}{|c|c|c|c|c|}
\hline & $\begin{array}{l}\text { Control } \\
(n=7)\end{array}$ & $\begin{array}{c}\text { DV obstruction } \\
(n=7)\end{array}$ & $\begin{array}{l}\text { Hypoxemia } \\
(n=5)\end{array}$ & $\begin{array}{l}\text { DV obstruction } \\
\text { and hypoxemia } \\
\quad(n=5)\end{array}$ \\
\hline \multicolumn{5}{|l|}{ Blood flow $(\mathrm{mL} / \mathrm{min} / \mathrm{kg})$} \\
\hline Combined ventricular output & $415 \pm 79$ & $407 \pm 87$ & $363 \pm 92$ & $325 \pm 59$ \\
\hline Umbilical-placental & $182 \pm 33$ & $178 \pm 40$ & $184 \pm 35$ & $174 \pm 56$ \\
\hline \multicolumn{5}{|l|}{ Blood flow $(\mathrm{mL} / \mathrm{min} / 100 \mathrm{~g})$} \\
\hline Left liver & $462 \pm 220$ & $632 \pm 337 \dagger$ & $366 \pm 167$ & $551 \pm 150+\S$ \\
\hline Right liver & $423 \pm 96$ & $645 \pm 22 \pm$ & $434 \pm 132$ & $677 \pm 345+\S$ \\
\hline Total liver & $428 \pm 72$ & $627 \pm 119+$ & $401 \pm 125$ & $619 \pm 222+\S$ \\
\hline Brain & $125 \pm 29$ & $132 \pm 24$ & $191 \pm 40$ & $190 \pm 67$ \\
\hline Heart & $138 \pm 22$ & $158 \pm 40$ & $299 \pm 136$ & $335 \pm 164$ \\
\hline Kidneys & $157 \pm 56$ & $153 \pm 61$ & $126 \pm 44$ & $95 \pm 44$ \\
\hline Gut & $65 \pm 20$ & $53 \pm 16$ & $53 \pm 26$ & $44 \pm 14$ \\
\hline Spleen & $271 \pm 132$ & $305 \pm 155$ & $363 \pm 195$ & $247 \pm 147$ \\
\hline Adrenal & $202 \pm 72$ & $203 \pm 61$ & $406 \pm 145$ & $409 \pm 42$ \\
\hline Lower carcass & $20 \pm 5$ & $18 \pm 4$ & $14 \pm 6$ & $12 \pm 4$ \\
\hline Upper carcass & $21 \pm 4$ & $22 \pm 2$ & $16 \pm 4$ & $12 \pm 7$ \\
\hline
\end{tabular}

* Values are given as mean $\pm \mathrm{SD}$. DV, ductus venosus.

$\dagger p<0.05$ v s control.

$\ddagger p<0.01 v s$ control.

$\S p<0.05$ vs hypoxemia.

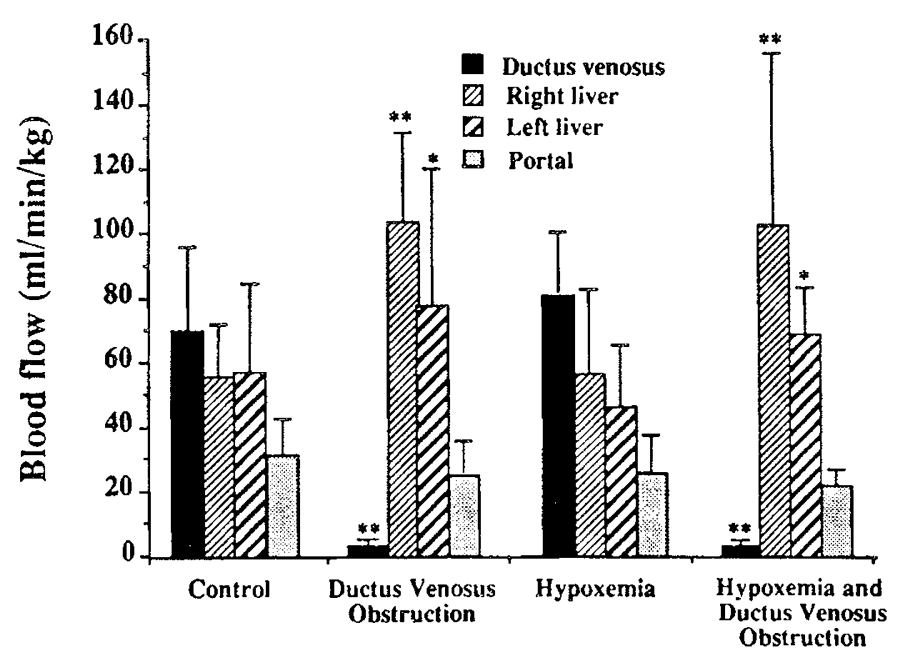

Fig. 2. Changes in liver blood flow, portal blood flow, and ductus venosus flow before and during ductus venosus obstruction in normoxemic $(n=7)$ and hypoxemic $(n=5)$ fetal lambs. ${ }^{*} p<0.05,{ }^{* *} p<0.005$.

flow increased from $56 \pm 16$ to $104 \pm 28 \mathrm{~mL} / \mathrm{min} / \mathrm{kg}$, accounting for the redistribution of all of the blood that passed through the ductus venosus before ductus venosus obstruction (Fig. 2). Thirty-two and $68 \%$ of the blood that would have passed through the ductus venosus was diverted through the left and right liver, respectively. Because the left liver accounted for $36 \%$ of the total liver weight, there appeared to be no preferential distribution of diverted ductus venosus flow to the left liver lobe. Hypoxemia alone tended to decrease liver blood flow and slightly increase the percentage of blood passing through the ductus venosus. The changes in liver blood flow after ductus venosus obstruction in hypoxemic animals were similar to those observed in the nonhypoxemic animals.

Vascular resistance across the umbilicus placenta and across the liver did not change after ductus venosus obstruction (Table 4). The combined resistance across the ductus venosus and liver increased from $0.013 \pm 0.006$ to $0.020 \pm 0.010 \mathrm{~mm} \mathrm{Hg} \cdot \mathrm{mL}^{-1}$. $\min ^{-1} \cdot \mathrm{kg}^{-1}$ fetal body weight $(p<0.05)$. As we have observed previously (13) during hypoxemia, there was a small but significant increase in hepatic vascular resistance from control values of $0.007 \pm 0.003$ to $0.013 \pm 0.008 \mathrm{~mm} \mathrm{Hg} \cdot \mathrm{mL}^{-1} \cdot \mathrm{min}^{-1} \cdot 100 \mathrm{~g}^{-1}$ $(p<0.05)$. Hepatic vascular resistance was not different from control values during combined ductus venosus obstruction and hypoxemia.

\section{DISCUSSION}

Our studies clearly demonstrate that preferential streaming of oxygen-rich blood to the brain and heart persists during obstruction of the ductus venosus in normoxemic and hypoxemic fetal lambs. Amoroso et al. (6) attempted to constrict the ductus venosus in three acutely exteriorized fetal lambs and noted no change in carotid arterial oxygen saturation or in arterial blood pressure. However, the lack of documentation of ductus venosus occlusion makes the validity of these observations questionable.

In our studies, we carefully documented obstruction of the ductus venosus and performed the studies at least $24 \mathrm{~h}$ after 
Table 4. Liver, umbilical-placental, and ductus venosus vascular resistance before and during ductus venosus obstruction in normoxemic and hypoxemic fetal lambs*

\begin{tabular}{lcccc}
\hline & Control & $\begin{array}{c}\text { DV obstruction } \\
(n=7)\end{array}$ & $\begin{array}{c}\text { Hypoxemia } \\
(n=5)\end{array}$ & $\begin{array}{c}\text { DV obstruction } \\
\text { and hypoxemia } \\
(n=5)\end{array}$ \\
\hline$\quad$ Vascular resistance $(\mathrm{mm} \mathrm{Hg} / \mathrm{mL} / \mathrm{min} / \mathrm{kg})$ & & & & \\
$\quad$ Umbilical-placental & $0.247 \pm 0.070$ & $0.246 \pm 0.060$ & $0.270 \pm 0.050$ & $0.300 \pm 0.097$ \\
$\quad$ Ductus venosus & $0.046 \pm 0.024$ & $1.683 \pm 0.791 \dagger$ & $0.053 \pm 0.023$ & $2.99 \pm 3.06 \dagger$ \\
$\quad$ Total liver & $0.021 \pm 0.011$ & $0.020 \pm 0.011$ & $0.038 \pm 0.021 \ddagger$ & $0.025 \pm 0.012$ \\
$\quad$ Ductus venosus and total liver & $0.013 \pm 0.006$ & $0.020 \pm 0.011 \ddagger$ & $0.022 \pm 0.011 \ddagger$ & $0.025 \pm 0.012 \ddagger$ \\
$\quad$ Vascular resistance (mm Hg/mL/min/100 g) & & & & $0.009 \pm 0.005$ \\
$\quad$ Left liver & $0.007 \pm 0.004$ & $0.008 \pm 0.005$ & $0.015 \pm 0.010$ & 0.009 \\
$\quad$ Right liver & $0.007 \pm 0.003$ & $0.007 \pm 0.004$ & $0.011 \pm 0.008$ & $0.008 \pm 0.004$ \\
$\quad$ Total liver & $0.007 \pm 0.003$ & $0.007 \pm 0.004$ & $0.013 \pm 0.009 \ddagger$ & $0.008 \pm 0.004$ \\
\hline
\end{tabular}

$*$ Values are given as mean $\pm \mathrm{SD}$. DV, ductus venosus.

$\dagger p<0.005 v s$ control.

$\ddagger p<0.05$ vs control.

surgery. We used an intraluminal balloon catheter to obstruct the ductus venosus. Previously, we have reported that 45 to $58 \%$ of the umbilical venous return passes through the ductus venosus $(3,13,14)$. In these studies, only $38 \%$ of the umbilical venous return passed through the ductus venosus, indicating that the catheter placement in the lumen of the ductus venosus may have partially obstructed blood flow through the ductus venosus. However, placement of the ductus venosus catheter does not alter placental or hepatic blood flow or change umbilical venous pressure, inasmuch as these values were in the same range that we have previously observed in similarly instrumented animals without ductus venosus catheter placement (14).

In the fetal lamb, streaming patterns in the inferior vena cava preferentially distribute highly oxygenated blood derived from the ductus venosus and left hepatic vein through the foramen ovale to supply the fetal brain, heart, and upper body (1). Less oxygenated blood from the inferior and superior vena cava is directed through the tricuspid valve to the right ventricle and pulmonary artery, and then is shunted across the ductus arteriosus, supplying the lower body. The ductus venosus and left hepatic vein join and enter the inferior vena cava through a common orifice. The lower margin of this orifice is covered by a thin valve-like membrane that appears to direct blood derived from these vessels toward the foramen ovale and thus to the upper body (8). Ductus venosus obstruction had no effect on the carotid artery oxygen content or regional organ oxygen delivery. Therefore, these streaming patterns must be maintained. After ductus venosus obstruction, the blood flow through the left liver, and therefore left hepatic vein, increases dramatically. The oxygen content of the blood in the left hepatic vein could also be expected to increase because hepatic uptake of oxygen will remain constant as flow is increased, thus hepatic $\mathrm{O}_{2}$ extraction will decrease (15). Thus, the blood flow and $\mathrm{O}_{2}$ content of blood passing through the common orifice of the ductus venosus and left hepatic vein into the inferior vena cava may not change substantially. In addition, the distribution of blood returning to the heart via the superior vena cava would not be expected to change after ductus venosus obstruction. These factors could explain the maintenance of the oxygen gradient between the blood in the ascending versus descending aorta during obstruction of the ductus venosus.

The fetal pig provides an interesting comparison to the sheep. The late gestation fetal pig lacks a ductus venosus but instead has intrahepatic vascular channels of over $100 \mu \mathrm{m}$ diameter in both lobes of the liver that allow umbilical venous return to bypass the hepatic sinusoids (16). Carotid artery saturation consistently exceeds descending aorta saturations during normoxemia and hypoxemia as in the lamb (17). This observation supports the view that the ductus venosus is not essential for the establishment of the streaming patterns in the inferior vena cava and right atrium that preferentially distribute highly oxygenated blood through the foramen ovale to the upper body.

Gilbert et al. (18) previously observed that the fetal sheep liver is extremely compliant, such that small changes in intrahepatic pressure lead to large changes in volume. Because the fetal liver contains $10-15 \%$ of the total blood volume, it is possible that alterations in the distribution of umbilical venous return regulate fetal hepatic volume. Increasing the quantity of blood shunted through the ductus venosus would decrease liver volume and increase fetal circulating blood volume. Stimuli that decrease fetal vascular volume, such as hemorrhage or umbilical cord compression, clearly have the greatest effect on the distribution of the umbilical venous return $(2,3)$. The mechanism controlling this redistribution remains unclear.

Due to the diversion of blood from the ductus venosus to the liver microcirculation, hepatic blood flow increased dramatically during ductus venosus obstruction. Despite this increase in flow, there was only a small change in umbilical venous pressure and there was no significant change in hepatic resistance to umbilical venous flow. Thus, in the fetus it is likely that the hepatic resistance sites are extremely distensible, as noted in adult cats (19). The site regulating resistance to venous flow in the fetal sheep liver is unclear. We confirmed our previous observations that fetal hepatic resistance to venous flow increases during hypoxemia (13). However, this response was blunted after ductus venosus obstruction. Lautt et al. (20) proposed that the major site of portal vascular resistance is beyond the sinusoid-central vein junction in small hepatic veins. In adult cats and dogs, a sphincter-like action in these small veins was demonstrated in response to hepatic nerve stimulation and to the infusion of norepinephrine and angiotensin $(21,22)$. It is possible that the increased liver blood flow after ductus venosus obstruction increases the cross-sectional diameter of similar small hepatic veins in fetal sheep, altering the magnitude of the resistance change during hypoxemia. Further studies will be required to determine if the intrahepatic sites of resistance to umbilical and portal venous blood flow in the fetal lamb are similar to those in the adult cat.

Acknowledgments. The authors gratefully acknowledge the skillful technical assistance of Christine Roman, Roger Chang, Bruce Payne, and Carl McWatters and the editorial assistance of Paul Sagan.

\section{REFERENCES}

1. Edelstone DI, Rudolph AM 1979 Preferential streaming of ductus venosus blood to the brain and heart in fetal lambs. Am J Physiol 237:H724-H729

2. Itskovitz J, LaGamma EF, Rudolph AM 1987 Effects of cord compression on fetal blood flow distribution and $\mathrm{O}_{2}$ delivery. Am J Physiol 252:H100-H109

3. Itskovitz J, Goetzman BW, Rudolph AM 1982 Effects of hemorrhage on umbilical venous return and oxygen delivery in fetal lambs. Am J Physiol 242:H543-H548 
4. Carter AM 1984 The blood supply to the abdominal organs of the fetal guinea pig. J Dev Physiol (Oxf) 6:407-416

5. Barclay AE. Franklin KJ, Prichard MML 1945 The Foetal Circulation. Charles C. Thomas, Springfield, IL

6. Amoroso EC, Dawes GS, Mott JC, Rennick BR 1955 Occlusion of the ductus venosus in the mature foetal lamb. J Physiol 129:64P-65P

7. Bristow J, Rudolph AM, Itskovitz J, Barnes R 1983 Hepatic oxygen and glucose metabolism in the fetal lamb: response to hypoxia. $J$ Clin Invest 71:1047-1061

8. Bristow JD, Rudolph AM, Itskovitz J 1981 A preparation for studying liver blood flow in the fetal lamb in utero. J Dev Physiol (Oxf) 3:255-266

9. Heymann MA, Payne BD, Hoffman JIE, Rudolph AM 1977 Blood flow measurements with radionuclide-labeled particles. Prog Cardiovasc Dis 20:55-79

10. Baer RW, Payne BD, Verrier ED, Vlahakes GJ, Moldowitch D, Uhlig PN, Hoffman JIE 1984 Increased number of myocardial blood flow measurements with radionuclide-labeled microspheres. Am J Physiol 246:H418H434

11. Edelstone DI, Rudolph AM, Heymann MA 1978 Liver and ductus venosus blood flows in fetal lambs in utero. Circ Res 42:426-433

12. Edelstone DI Rudolph AM Heyman MA 1980 Effects of hypoxemia and decreasing umbilical blood flow on liver and ductus venosus blood flows in fetal lambs. Am J Physiol 238:H656-H663

13. Paulick RP, Meyers RL, Rudolph CD, Rudolph AM 1991 Venous responses to hypoxemia in the fetal lamb. J Dev Physiol (Oxf) (in press)
14. Edelstone DI, Rudolph AM, Heymann MA 1980 Effects of hypoxemia and decreasing umbilical flow on liver and ductus venosus blood flows in fetal lambs. Am J Physiol 238:H656-H663

15. Rudolph CD, Roman C, Rudolph AM 1989 Effect of acute umbilical cord compression on hepatic carbohydrate metabolism in the fetal lamb. Pediatr Res 25:228-233

16. Silver M, Barnes RJ, Comline RS, Burton GJ 1982 Placental blood flow: some fetal and maternal cardiovascular adjustments during gestation. J Reprod Fertil [Suppl] 31:139-160

17. Silver M, Barnes RJ. Fowden AL, Comline RS 1988 Preferential oxygen supply to the brain and upper body in the fetal pig. Adv Exp Med Biol 222:683687

18. Gilbert RD, Genstler CC, Dale PS, Power GG 1981 Compliance of the fetal sheep liver. J Dev Physiol (Oxf) 3:283-295

19. Greenway CV, Lautt WW 1988 Distensibility of hepatic venous resistance sites and consequences on portal pressure. Am J Physiol 254:H452-H458

20. Lautt WW, Greenway CV, Legare DJ, Weisman H 1987 Localization of intrahepatic portal vascular resistance. Am J Physiol 251:G373-G381

21. Legare DJ, Lautt WW 1987 Hepatic venous resistance site in the dog: Localization of intrahepatic pressure measurements. Can J Physiol Pharmacol 65:352-359

22. Lautt WW, Greenway CV, Legare DJ 1987 Effects of hepatic nerves, norepinephrine, angiotensin and elevated central venous pressure on postsinusoidal resistance sites and intrahepatic pressures in cats. Microvasc Res 33:50-61 